\title{
Desautomatización fraseológica: de la norma a la creatividad
}

\section{Phraseological Modifications: from Norm to Creativity}

\author{
Elisabeth LLOPART SAUMELL \\ Universidad de Alicante \\ elisabet.llopart@ua.es
}

Resumen: Este artículo se propone indagar en la transgresión de la norma que la desautomatización fraseológica supone respecto de las unidades fraseológicas (UF) compartidas por los hablantes de una comunidad lingüística. Mientras las UF forman parte de los usos normales de una lengua, la desautomatización constituye una desviación respecto de estos usos. De todas formas, estas modificaciones están previstas en el sistema de la lengua, de acuerdo con los conceptos de norma y sistema de Coseriu (1952). Además, como la UF desautomatizada se usa para causar unos efectos determinados en el receptor, se emplean estrategias discursivas para asegurar su comprensión. A partir de aquí, se pueden observar algunos patrones que rigen la desautomatización fraseológica y que se basan tanto en el sentido literal de la UF original, como en su carácter idiomático.

Palabras clave: fraseología; desautomatización; norma; creatividad; valor estilístico.

Abstract: The aim of this article is to investigate the transgression of the norm that phraseological manipulations imply with respect to phraseological units (PUs), which are shared by the speakers of a linguistic community. While PUs are part of the normal use of a language, phraseological manipulations deviate from this normal use. However, the language system allows these modifications, according to Coseriu's concepts of norm and system (Coseriu 1952). In addition, since the manipulated PU seeks to cause 
certain effects on the receiver, discursive strategies are used to ensure communication. In this sense, phraseological manipulations show some defined patterns, which are based both on the literal meaning of the original PU and its idiomatic character.

Keywords: Phraseology; Phraseological Manipulation; Norm; Creativity; Stylistic Value.

\section{INTRODUCCIÓN}

La desautomatización constituye una cuestión de interés en fraseología, como demuestran los numerosos trabajos dedicados a este fenómeno lingüístico. En particular, uno de los temas que ha centrado notablemente la atención es la motivación o los fines comunicativos de estas unidades fraseológicas modificadas respecto de las formas conocidas por los hablantes, ya que forman parte del conocimiento enciclopédico y compartido por los miembros de una comunidad lingüística. En este sentido, se han propuesto algunas clasificaciones, de acuerdo con la motivación y el procedimiento de las unidades fraseológicas desautomatizadas (Martí-Sánchez 2015), y se ha estudiado el valor afectivo (Moreno Nilo 2015), la ironía que desprenden (Timofeeva 2005), las connotaciones asociadas (Zuluaga 2001), la intensificación del enunciado (Guerrero Salazar 2017), el carácter lúdico (Timofeeva 2009) y la finalidad estética (Sanmartín Ortí 2006), entre otros efectos (Díaz Orozco 2016), partiendo tanto de textos periodísticos, como publicitarios y literarios. Desde un punto de vista descriptivo y práctico, conocer el efecto que provocan resulta necesario para detallar las distintas tipologías y superar la dificultad añadida que supone la desautomatización fraseológica para la traducción, puesto que tiene implicaciones semánticas, pragmáticas y estilísticas (Mena Martínez 2003).

No obstante, la desautomatización de las unidades fraseológicas aún no dispone de una teoría que dé cuenta de toda la complejidad que subyace tras la manipulación de estas expresiones fijas. Por este motivo, el objetivo de este trabajo consiste en analizar las modificaciones formales (Timofeeva 2009) de este fenómeno fraseológico en el marco del concepto de norma de Coseriu (1952), entendida en relación con del uso y el sistema de la lengua, ya que «entre las variantes admitidas por el sistema, [...] una suele ser la normal, mientras las demás, o resultan anormales, o tienen determinado valor estilístico" (Coseriu 1952, 51). En palabras de Hanks, la norma se utiliza como base para contrastar un uso no usual o creativo (Hanks 2013). Ahora bien, si tenemos en cuenta que, aunque la desautomatización fraseológica transgreda la norma establecida en el uso, forma parte del sistema de la lengua y debe ser comprensible para el receptor para asegurar la comunicación entre ambos interlocutores, observamos que se establecen unos patrones que toman como base la unidad fraseológica original. Estos patrones están relacionados, por un lado, con la literalidad del fraseologismo y, por el otro, con su carácter idiomático. Si mantienen parte del sentido literal además

Elisabeth LLOPART SAUMELL Desautomatización fraseológica: de la norma a la creatividad
CLINA

vol. 6-2, December 2020, 119-136

elSSN: 2444-1961

Ediciones Universidad de Salamanca - CC BY-NC-ND 
del sentido idiomático, la unidad fraseológica (UF) desautomatizada resulta más fácil de reconocer que si presenta solamente el sentido idiomático, como veremos.

\section{FRASEOLOGÍA Y DESAUTOMATIZACIÓN}

Las unidades fraseológicas se definen como "combinaciones estables de unidades léxicas formadas por más de dos palabras gráficas y cuyo límite superior se sitúa en el nivel de la oración compuesta» (Corpas Pastor 1997, 269). Este tipo de unidades léxicas incluyen tres tipos de realizaciones o esferas: las colocaciones, las locuciones y los enunciados fraseológicos (Corpas Pastor 1997, 50). Además, reciben, también, otras denominaciones. Desde modismo, frase hecha, fraseologismo o frasema, a expresión fija o unidad pluriverbal. Así pues, a partir de esta definición y de las distintas denominaciones, se desprende que las UF constituyen un sintagma formado por unas palabras determinadas que se combinan en un orden preestablecido y que presentan cierto grado de idiomaticidad. Aun así, estas unidades pueden presentar variación (Montoro del Arco 2005, 126-127):

1. El orden de los constituyentes se puede ver alterado.

2. La categoría gramatical puede variar.

3. El número de elementos que las componen pueden ser modificados.

4. Los constituyentes pueden sustituirse por otros.

Respecto de la variabilidad fraseológica, algunos casos se consideran formulaciones diferentes de una misma UF, es decir, se trata de distintas variantes de una misma unidad. Por ejemplo, andar o estar alguien de capa caída (Montoro del Arco 2005: 129) o importar un bledo e importar un pito (Montoro del Arco 2005: 139), en las cuales se observa variación léxica; echar (alguien) una cana o una canita al aire (Montoro del Arco 2005: 140), con variación morfológica; o estar alguien echo un pato, o un pato de agua $(D L E)$, que se trata de una variación estructural, en este caso, por extensión. En cambio, otros tipos de variación se consideran desautomatizaciones fraseológicas, puesto que presentan modificaciones creativas con finalidades estilísticas respecto de una UF determinada (Zuluaga 1980, Corpas Pastor 1997, Mena Martínez 2003, Montoro del Arco 2005). En este trabajo, nos centramos en este segundo tipo de variación fraseológica y, concretamente, en las modificaciones de tipo formal (Montoro del Arco 2005, Timofeeva 2009). La desautomatización formal hace referencia, principalmente, a las adiciones o supresiones en la estructura de la UF, como en sangre azulgrana (de sangre azul) (Timofeeva 2009, 256) o sin guerra ni gloria (de sin pena ni gloria) (Montoro del Arco 2005, 148)'.

1. Se trata de un ejemplo atribuido al escritor Gabriel García Márquez (Zuluaga 1997, 636; citado en Montoro del Arco 2005, 148).

Elisabeth LLOPART SAUMELL Desautomatización fraseológica: de la norma a la creatividad
CLINA

vol. 6-2, December 2020, 119-136

elSSN: 2444-1961

Ediciones Universidad de Salamanca - CC BY-NC-ND 
La desautomatización morfológica se caracteriza por ser una modificación novedosa y con afán creativo respecto de la unidad fijada y con carácter idiomático que se produce de forma voluntaria e intencionada con una finalidad determinada por parte del emisor para conseguir un efecto expresivo y sorprendente para el destinatario (Mena Martínez 2003; Montoro del Arco 2005, 136). En este sentido, cuando hablamos de un valor o efecto estilístico o expresivo, o de la finalidad o motivación de este tipo, hacemos referencia al hecho que la intención comunicativa de la desautomatización va más allá del sentido idiomático de la UF modificada, haciendo que «la realidad se perciba con una mayor fuerza y duración» (Gurillo 1997, 21). De acuerdo con los saberes lingüísticos de Coseriu (Coseriu 1992), se diferencian dos tipos de alteraciones presentes en una UF: mientras la variación fraseológica es el resultado del saber idiomático de acuerdo con el significado del contenido en el plano de una lengua determinada, la desautomatización fraseológica es el resultado del saber expresivo de acuerdo con el sentido del contenido en el plano discursivo (Montoro del Arco 2005, 136). Respecto del plano discursivo, el autor hace hincapié en el hecho que se persigue un efecto contextual, de modo que posiblemente se usen otras estrategias discursivas para conseguir este objetivo, además de la manipulación o modificación fraseológica.

\section{NORMA, CREATIVIDAD Y EXPLOTACIÓN}

La fraseología forma parte de los usos normales y compartidos por los hablantes de una lengua determinada. En cambio, la desautomatización fraseológica, en su afán creativo, se aleja de la forma ya conocida por los hablantes y causa unos efectos determinados en el receptor. A continuación, valoramos el fenómeno de la desautomatización a partir del concepto de norma de Coseriu (1952), que no se basa en valores subjetivos y de corrección, sino en el uso:

Aclaramos además que no se trata de la norma en el sentido corriente, establecida o impuesta según criterios de corrección y de valoración subjetiva de lo expresado, sino de la norma objetivamente comprobable en una lengua, la norma que seguimos necesariamente por ser miembros de una comunidad lingüística y no aquella según la cual se reconoce que 'hablamos bien' o de manera ejemplar, en la misma comunidad (Coseriu 1952, 53).

Igualmente, entre las diferentes variantes posibles de acuerdo con el sistema de la lengua, podemos diferenciar, por un lado, la variante considerada normal, puesto que se basa en la norma, es decir, en el uso, y, por el otro, las variantes anormales, que transgreden las normas de uso y, en general, se estima que presentan un determinado valor estilístico (Coseriu 1952, 51):

Asimismo, es evidente que no todas las asociaciones posibles en el sistema (por el lado del contenido o por el lado de la forma) se dan también en la norma: considérese que la

Elisabeth LLOPART SAUMELL Desautomatización fraseológica: de la norma a la creatividad
CLINA

vol. 6-2, December 2020, 119-136

elSSN: 2444-1961

Ediciones Universidad de Salamanca - CC BY-NC-ND 
labor creativa en el lenguaje, y en particular la labor poética, consiste en gran parte en descubrir cada vez nuevas asociaciones significativas (imágenes) o formales (rima, asonancia, aliteración, armonía imitativa, etc.), posibles en el sistema (es decir, virtualmente existentes), pero inéditas en la norma. (Coseriu, 1952: 52)

Así pues, la norma se utiliza como base para contrastar un uso no usual o creativo; en palabras de Hanks (2013, 212), «a creative exploitation»:

An exploitation is a deliberate departure from an established pattern of normal word use, either in order to talk about new or unusual things or in order to say old things in a new, interesting, or unusual way. Exploitations are part of the natural human habit of playing with language, but they can also serve a serious purpose, especially in cases where a more well-established way of talking about a particular event, situation, or entity is not available. [...] In some cases, an exploitation may push the possibilities of language to extremes. In other cases, exploitations say what needs to be said and be hardly noticeable until a lexical analyst comes along and draws attention to them. (Hanks 2013, 212)

Ciertamente, la desautomatización fraseológica no forma parte de la norma compartida por una comunidad lingüística, es decir, de las realizaciones normales de sus hablantes. En este sentido, las UF modificadas transgreden la norma, pero tienen en cuenta el sistema de la lengua, ya que deben ser comprensibles para el receptor para asegurar la comunicación, aunque sean unidades novedosas y sorprendentes. La desautomatización forma parte, pues, de «las necesidades expresivas cotidianas de cualquier hablante» (Coseriu 1952, 46), de modo que, aunque algunos estudios se basan en textos literarios, el uso de formas creativas de la fraseología compartida por los hablantes de una lengua se plasma en textos periodísticos y publicitarios, pero también en la lengua coloquial (Ruiz Gurillo 1997). En cuanto a la desviación o explotación respecto de la norma lingüística, es decir, del uso, la motivación es principalmente estilística (Coseriu 1952; Hanks 2013)², para ser original, llamar la atención, causar sorpresa, hacer reír, ser irónico, etc. En este sentido, "one measure of originality is surprise effect» (Koestler 1975, 83), ya que este efecto sorpresa genera una reacción en el receptor por el hecho de ser un resultado no previsible o esperable. La desautomatización fraseológica contribuye, pues, a la persistencia y memorización del mensaje, porque su comprensión requiere un mayor esfuerzo cognitivo, como ocurre también con las metáforas (Sánchez Manzanares 2003, 746) o los neologismos (Autor 2014).

En definitiva, el concepto de norma de Coseriu (1952) juntamente con el concepto de explotación de Hanks (2013) constituyen nociones relevantes para estudiar el fenómeno de la desautomatización fraseológica. Por un lado, nos ayudan a identificar las desautomatizaciones fraseológicas y a explicar la motivación de este fenómeno en el sistema de la lengua. Por el otro, como veremos en el análisis de diferentes ejemplos

2. Cabe tener en cuenta que la norma también se puede transgredir por desconocimiento. En este caso, no existe, pues, una finalidad expresiva o estética.

Elisabeth LLOPART SAUMELL Desautomatización fraseológica: de la norma a la creatividad
CLINA

vol. 6-2, December 2020, 119-136

elSSN: 2444-1961

Ediciones Universidad de Salamanca - CC BY-NC-ND 
(§ 4), permiten observar que la modificación deliberada y con afán creativo y expresivo de la UF original parte tanto del sentido literal de dicho fraseologismo como de su carácter idiomático.

\section{ANÁLISIS}

En la desautomatización fraseológica de tipo formal (Timofeeva 2009), podemos observar algunos patrones en relación con la transgresión de la norma, es decir, de la UF original que forma parte del conocimiento compartido por los hablantes. En este sentido, la manipulación de una UF con una intención estilística o expresiva tiene en cuenta, por un lado, el carácter idiomático de la unidad y, por el otro, el carácter literal o la imagen mental que la lectura literal de dicha unidad produce en el hablante. En este apartado analizamos las desautomatizaciones a partir de dos fraseologismos muy frecuentes con componente animalístico: dar gato por liebre y coger el toro por los cuernos. La desautomatización de estas dos locuciones es muy productiva, ya que existen múltiples variaciones en que gato y liebre, en la primera UF, y toro, en la segunda, son sustituidos por otras realizaciones.

Los diferentes ejemplos de desautomatización fraseológica que presentamos a continuación se han obtenido a partir de una búsqueda por internet de las dos UF desautomatizadas. Para ello, hemos realizado una búsqueda avanzada de Google ${ }^{3}$ en que los componentes del fraseologismo presentaran el mismo orden, pero en que uno de esos componentes fuera sustituido por otra unidad léxica diferente a la original. En el caso de dar gato por liebre indicamos, en una primera búsqueda, que en vez de la palabra gato presentara otra unidad léxica («dar * por liebre» -gato) y, en una segunda búsqueda, hicimos lo mismo con liebre ("dar gato por * "liebre). En cuanto a coger el toro por los cuernos ${ }^{4}$, buscamos sustituir toro por otra unidad léxica ("coger el * por los cuernos» -toro). De los diferentes resultados obtenidos, seleccionamos un conjunto de ejemplos procedentes de periódicos, revistas y blogs, principalmente, para que limitar los géneros textuales de las fuentes consultadas.

La locución verbal dar gato por liebre significa 'engañar en la calidad de algo por medio de otra cosa inferior que se le asemeja', de acuerdo con el Diccionario de la lengua española (DLE) de la Real Academia Española. Por otro lado, la fraseologización se corresponde con un proceso de cambio semántico (Sánchez López, 2015), de modo que, en origen, esta expresión se utilizaba de forma literal: en la Edad Media se

3. Búsqueda avanzada de Google: https://www.google.es/advanced_search.

4. Esta locución admite cierta variación, como se indica en el DLE: coger el, o al, toro por las astas, o por los cuernos. En este análisis solamente hemos tomado en consideración coger el toro por los cuernos, para focalizar la búsqueda de la desautomatización en una sola variante y evitar las repeticiones.

Elisabeth LLOPART SAUMELL Desautomatización fraseológica: de la norma a la creatividad
CLINA

vol. 6-2, December 2020, 119-136

elSSN: 2444-1961

Ediciones Universidad de Salamanca - CC BY-NC-ND 
extendió el engaño de ofrecer gato en vez de liebre debido al parecido entre ambos animales y el menor coste económico del primero. Además, actualmente observamos que, en algunos casos, el significado de este fraseologismo se ha simplificado respecto de la definición del $D L E$, puesto que se utiliza simplemente para expresar un engaño o fraude, aun cuando no hay una comparación entre la calidad de dos productos similares ( $p$. ej., en el marco de un artículo titulado El neurofraude de las pseudociencias (Pou 2020), en que esta UF se usa como nota final: «Y ya sabes... Qué [sic] no te den gato por liebre", como equivalente de vender la moto a alguien, definida como 'Tratar de convencerlo de algo con mucha labia, especialmente si es falso o poco creíble' $(D L E)$ ). A partir de estas premisas, en este caso concreto podemos distinguir tres patrones de modificación de la UF original que juegan con el sentido de 'engaño'.

Para establecer estos patrones, hemos analizado tanto el sentido literal como el sentido idiomático de la UF original, y hemos descrito la imagen mental que se desprende de dicha unidad. Para ello, hemos tenido en cuenta de forma muy simplificada el esquema del proceso de fraseologización (Sánchez López 2015, 174)5.

\begin{tabular}{|l|l|l|l|}
\hline UF original & Sentido literal & Sentido idiomático & $\begin{array}{l}\text { Sentido idiomático } \\
\text { simplificado }\end{array}$ \\
\hline Significado & - & $\begin{array}{l}\text { 'Engañar en la calidad de } \\
\text { algo por medio de otra cosa } \\
\text { inferior que se le asemeja' }\end{array}$ & 'Engañar' \\
\hline Imagen mental & Comida & - & - \\
\hline
\end{tabular}

Tabla 1. Representación del significado de la UF original dar gato por liebre.

A partir de aquí, de acuerdo con las desautomatizaciones estudiadas, hemos podido observar cómo se agrupaban las UF desautomatizadas de acuerdo con las características que presentan, como se observa en la Tabla 2:

\begin{tabular}{|l|c|c|c|}
\hline UF desautomatizada & $\begin{array}{c}\text { Patrón 1: carácter } \\
\text { semiliteral e idiomático }\end{array}$ & $\begin{array}{c}\text { Patrón 2: carácter } \\
\text { idiomático }\end{array}$ & $\begin{array}{c}\text { Patrón 3: carácter } \\
\text { idiomático simplificado }\end{array}$ \\
\hline Sentido literal & $\mathrm{x}$ & - & - \\
\hline Sentido idiomático & $\mathrm{x}$ & $\mathrm{x}$ & $\mathrm{x}$ \\
\hline $\begin{array}{l}\text { Sentido idiomático } \\
\text { simplificado }\end{array}$ & - & - & \\
\hline Significado & $\begin{array}{l}\text { De calidad o clase inferior } \\
\text { en el ámbito gastronómico } \\
\text { o alimentario }\end{array}$ & $\begin{array}{l}\text { De calidad o clase } \\
\text { inferior }\end{array}$ & Engaño \\
\hline
\end{tabular}

Tabla 2. Patrones de desautomatización formal de dar gato por liebre.

5. A diferencia de la autora, en este trabajo usamos la noción de imagen (mental) en relación con el sentido literal de la unidad como base para la desautomatización.

Elisabeth LLOPART SAUMELL Desautomatización fraseológica: de la norma a la creatividad
CLINA

vol. 6-2, December 2020, 119-136

elSSN: 2444-1961

Ediciones Universidad de Salamanca - CC BY-NC-ND 
En el primer patrón, con carácter semiliteral e idiomático, encontramos los casos más apegados al sentido original, puesto que se mantiene la referencia al hecho de comparar dos productos, uno de los cuales es de calidad o clase inferior, y pertenece al ámbito gastronómico o alimentario. En el segundo patrón, de carácter idiomático, agrupamos las desautomatizaciones que mantienen el sentido idiomático de comparación entre dos elementos de diferente calidad o clase, haciendo hincapié en la inferioridad de uno de los referentes. Finalmente, en el tercer grupo, con carácter idiomático simplificado, clasificamos aquellas modificaciones fraseológicas que, aunque formalmente parecen mantener la comparación, solo expresan el sentido de engaño.

En relación con el primer grupo, encontramos algunas desautomatizaciones en que gato o liebre se ha sustituido por otro alimento. Aunque, como veremos, el parecido entre el gato o la liebre, y el alimento en cuestión es inexistente, a diferencia de lo que ocurre con los dos elementos de referencia en la expresión original, estas desautomatizaciones mantienen el sentido culinario. Por lo tanto, comprender el significado de la UF modificada resulta fácil para el lector. Por otro lado, debemos tener en cuenta que en el fraseologismo dar gato por liebre, la palabra gato es el elemento de la comparación que presenta una calidad inferior y, por tanto, se trata del producto mediante el cual se produce el engaño, mientras que liebre se relaciona con el producto de calidad y, por tanto, con el artículo esperado por el usuario o receptor. En las desautomatizaciones con la estructura dar x por liebre, gato se ha sustituido por perca y apio (ej. 1-2):

(1) Pesadillaenlacocinao cómo darperca por liebre. [20minutos. Fechadeacceso: 7 de junio de 2020. https://blogs.20minutos.es/reality-blog-show/2014/03/12/ pesadilla-en-la-cocina-o-como-dar-perca-por-liebre/]

(2) La revolución de la carne (de mentira) ya está en marcha

Estas empresas están llevando la 'sustitución alimentaria' al siguiente nivel. Nada de aburridos bistecs de tofu, basta de llamar albóndiga vegetariana a algo solo porque sea redondo. Y van en serio: Mark Bittman, periodista gastronómico del New York Times, dijo que «no notarás la diferencia entre esto y pollo real. Al menos yo no pude y es el tipo de cosas que hago para ganarme la vida». ¿Nos quieren dar apio por liebre? [Xataka. Fecha de acceso: 7 de junio de 2020. https://www.xataka.com/medicina-y-salud/la-revolucion-de-lacarne-de-mentira-ya-esta-en-marcha]

En el contexto del ejemplo (1), se describen varias escenas del programa televisivo Pesadilla en la cocina. Entre los distintos alimentos que comentan aparece la perca, que, en palabras del autor del texto, «es uno de los peores pescados que hay junto con la panga». En el artículo se indica que los restauradores «servían perca y decían que era mero». De modo que ahí radica el engaño, ya que ofrecen un producto que se asemeja a otro de mayor calidad. La entrada de este blog podría llevar por título «Pesadilla en la cocina o cómo dar perca por mero". Ahora bien, al mantener uno de los dos sus-

Elisabeth LLOPART SAUMELL Desautomatización fraseológica: de la norma a la creatividad
CLINA

vol. 6-2, December 2020, 119-136

elSSN: 2444-1961

Ediciones Universidad de Salamanca - CC BY-NC-ND 
tantivos de la UF original permite llegar más fácilmente a la definición de esta locución, aunque el resultado final no sea literal. De este modo, llama más la atención. Respecto del ejemplo (2), dar apio por liebre, hace referencia a la elaboración de alimentos que imitan la carne, tanto en aspecto como en sabor, pero que son veganos. De ahí el «engaño» al cual hace referencia el autor del artículo, aunque la motivación de este tipo de alimento no sea engañar al público, sino favorecer la dieta vegana. Para mantener esta referencia al veganismo, utilizan la palabra apio, como cliché de la alimentación vegana o vegetariana.

En cuanto a las UF desautomatizadas con la estructura dar gato por $x$, en vez de liebre encontramos cerdo, centollo de mar, trufa y makis (ej. 3-6):

(3) Con las extremidades posteriores del cerdo pueden elaborarse obres maestras como el jamón ibérico o algunos perniles serranos que hacen bueno el dicho de dar gato por cerdo, por no hablar de los fiambres de jamón, cuyas proteínas ni siquiera proceden en exclusividad de los cuartos traseros del gorrino. [El Mundo. Fecha de acceso: 7 de junio de 2020. https://www.elmundo. es/salud/1994/103/00192.html]

(4) Que no te den "gato" por centollo esta Navidad: los tres detalles para saber que es gallego. [CLM24. Fecha de acceso: 7 de junio de 2020. https:// www.clm24.es/articulo/viral/den-gato-centollo-navidad-detalles-saber-es-gallego/20181117124333226125.html]

(5) Cocina flojísima. No hay sabor. Para colmo me intentan dar gato por trufa. [Tripadvisor. Fecha de acceso 7 de junio de 2020. https://www.tripadvisor. es/ShowUserReviews-g187514-d775579-r468093211-Luna_Rossa-Madrid. html]

(6) Aquellos primeros tiempos en donde se nos podía dar gato por maki quedan sepultados en el pasado, y el foodie cultivado tiene las antenas bien dirigidas hacia las propuestas de calidad. [Revista GQ. Fecha de acceso: 7 de junio de 2020. https://www.revistagq.com/la-buena-vida/comer-y-beber/articulos/losmejores-platos-del-mes-en-madrid-octubre-2016/24813]

En todos estos ejemplos, a diferencia de la expresión original, no se indica que el alimento ofrecido no sea realmente lo que dice ser, sino que pone el énfasis en la dudosa calidad del producto, como se indica en el caso del maki (ejemplo 6): «el foodie cultivado tiene las antenas bien dirigidas hacia las propuestas de calidad». En otros casos, se especifica la baja calidad del producto. Ya sea, por ejemplo, porque además del alimento indicado lleve otros ingredientes, como en dar gato por cerdo (3), en que el engaño recae en el hecho de que algunos jamones cocidos contienen otros productos que no son cerdo, como puede ser la lactosa. También se pone en duda la calidad 
en relación con el origen del producto, como en el caso del centollo (4). Y, finalmente, en el hecho de que el alimento no sea fresco, como ocurre con la trufa (5), y, por tanto, la calidad del producto sea inferior a la esperada en cuanto a aroma y sabor.

En otros ejemplos, aunque liebre se sustituye por otro producto alimentario, como un plato gurmé o un transgénico, no se hace referencia a la baja calidad del artículo, sino que se pone en entredicho que realmente se trate de ese producto (ej. 7-8):

(7) La carne 'mechá' y las muñecas rusas.

Es como todo, la crisis de la listeriosis. Por encima del daño hecho y de los subterfugios empresariales por dar gato por plato gurmé, la administración ha demostrado una dejación de funciones clamorosa. [La Voz de Cádiz. Fecha de acceso: 7 de junio de 2020. https://www.lavozdigital.es/opinion/lvdi-carne-mecha-y-munecas-rusas-201909010942_noticia.html?ref=https:\%2F\%2Fwww.google.es\%2F]

(8) Una de sus primeras iniciativas ha sido la creación de un banco de semillas abierto a todos aquellos huerteros que quieran compartirlas o intercambiarlas. Eso sí, ecológicas. No vayáis a dar gato por transgénico. [La red de huertos comunitarios de Madrid. Fecha de acceso: 7 de junio de 2020. https://redhuertosurbanosmadrid.wordpress.com/page/112/?pages-list]

Por otro lado, en el caso de dar gato por transgénico, la sustitución de liebre por transgénico no resulta adecuada si tenemos en cuenta que la referencia al gato designa el producto de calidad inferior mientras que la liebre es el producto esperado. Por este motivo, aunque la referencia al engaño y a la calidad es comprensible porque la estructura de la locución mantiene elementos de la UF original, la forma desautomatizada dar transgénico por liebre sería más acertada.

Otro ejemplo relacionado con la alimentación es dar ecológico por liebre (ej. 9). De nuevo, parece que la UF se ha modificado de forma incorrecta, puesto que, aunque la desautomatización fraseológica siguiente presenta la idea de engaño en relación con los productos ecológicos, la formulación sería más comprensible y adecuada si se correspondiera con dar gato por ecológico. Aun así, el significado se puede entrever, pero más por la relación que mantiene con la UF original que por el modo como se ha formulado esta modificación.

(9) En caso de no encontrar el establecimiento en cuestión, no podemos tener garantía de que este comercio nos esté dando ecológico «por liebre» y, en consecuencia, nos estén cobrando un precio superior por un producto convencional. [El País. Fecha de acceso: 7 de junio de 2020. https://blogs. elpais. com/a-gusto-del-consumidor/2016/04/ecol\%C3\%B3gico-posible-fraude. $\mathrm{html]}$

Elisabeth LLOPART SAUMELL Desautomatización fraseológica: de la norma a la creatividad
CLINA

vol. 6-2, December 2020, 119-136

elSSN: 2444-1961

Ediciones Universidad de Salamanca - CC BY-NC-ND 
En cuanto a los ejemplos que presentan el segundo patrón, podemos observar que la desautomatización se aleja del sentido alimentario a los cuales remonta el sentido literal de la UF original, pero mantiene la comparación, ya sea en relación con la calidad del producto, o porque parecen ser de la misma clase. Respecto de la estructura dar x por liebre, observamos dar dato por liebre, dar Federer por liebre y dar «follow» por liebre (ej. 10-12):

(10) Oñate afirma que el Gobierno regional quiere dar «dato por liebre» a los murcianos con los resultados de la encuesta del CEMOP

EI PSOE califica como una "gran mentira» los datos ofrecidos hoy, y acusa al Gobierno regional de haber obligado a la empresa a "cocinar» los resultados para ocultar una bajada de 8,5 puntos de intención de voto al Partido Popular. [Murcia.com. Fecha de acceso: 7 de junio de 2020. https://www.murcia.com/ region/noticias/2011/02/04-onate-afirma-gobierno-regional-quiere.asp]

(11) Hablar cuesta poco, escribir cuesta menos, pero a nosotros, los que hemos mamado el tenis desde nuestra infancia, no nos pueden dar Federer por liebre. Detectamos rápidamente, allá por 2004, las nuevas técnicas traídas por Federer a este deporte: partidos fríos, no jugar la Davis, basar su gris juego en el ace, fracasar con estrépito en arcilla, etc. [Marca. Fecha de acceso: 7 de junio de 2020. https://www.marca.com/tenis/2018/06/20/5b2aa60c268e3e012b8b45f8.htm]

(12) Risas aparte. Al final, esto de dar follow por liebre termina cantando ópera. El prestigio es una cosa que difícilmente vas a conseguir con 80 millones de amiguetes en Facebook ni porque te compres unos compadres a los que les hagas un follow me. [Comunidad hostelsur. Fecha de acceso: 7 de junio de 2020. http://comunidad.hosteltur.com/post/2012-01-25-se-venden-seguidores-de-twitter-a-15-cntimos-la-docena.html]

En el ejemplo (10), en que la palabra gato ha sido sustituida por dato, se apela a la supuesta manipulación de los datos ofrecidos acerca de una encuesta sobre la intención de voto de los ciudadanos, de modo que los datos o resultados no son correctos. En este caso, además, la palabra dato presenta similitud formal con gato, puesto que solo cambia la primera letra: la $g$ se sustituye por una $d$. Aquí, el engaño no subyace directamente en la calidad del producto ofrecido, sino en el hecho que lo que se ofrece es fruto de un engaño, una mentira. De modo que, aunque hasta cierto punto se asemeja a los resultados obtenidos, estos han sido manipulados. Por otro lado, en el ejemplo (11), dar Federer por liebre, sí que se hace referencia a la mala calidad ofrecida por el tenista Roger Federer. No en relación con los resultados obtenidos, sino por su estilo de juego y las estrategias usadas. En este sentido, el autor de la UF desautomatizada lo considera un mal ejemplo de lo que verdaderamente es el tenis. 
Por este motivo, Federer no llega a ser «liebre», es decir, un buen exponente de este deporte. Finalmente, en dar follow por liebre (12) se hace referencia a una noticia que habla sobre la posibilidad de comprar followers ('seguidores') en varias redes sociales. Como se observa en el contexto, se indica que tener más seguidores, si su follow ha sido comprado, no es igual a tener prestigio o fama. De este modo, se infiere que un follow no equivale a prestigio, aunque ambas nociones se asemejen.

En relación con la estructura dar gato por $x$ del segundo patrón, podemos observar ejemplos como los siguientes: dar gato por libro, por contrato y por Puigdemont (ej. 13-15).

(13) La Junta da «gato por libro» con el nuevo Releo Plus Fapava denuncia que la Administración regional presenta un «supuesto» programa de gratuidad de libros de texto para el curso 2017/2018 que supone el fin de la exitosa experiencia del año pasado. [Último Cero. Fecha de acceso: 7 de junio de 2020. https://ultimocero.com/noticias/2017/03/21/la-junta-dagato-por-libro-con-el-nuevo-releo-plus/]

(14) Una cosa es ser torpe e incluso negligente y otra es ser tonto de remate y si el deán captó enseguida que Castiñeiras le quería dar gato por contrato no se comprende que en diez años no sospechara del personaje. [Libertad Digital. Fecha de acceso: 7 de junio de 2020. https://www.libertaddigital.com/opinion/ cesar-vidal/el-enigma-castineiras-64990/]

(15) Pero ¿cómo probar que es Puigdemont quien está tras la pantalla de plasma? Actualmente, la técnica del disfraz ha alcanzado cotas muy sofisticadas y con pasmosa facilidad se podría dar gato por Puigdemont. [El Imparcial. Fecha de acceso: 7 de junio de 2020. https://www.elimparcial.es/noticia/186176/ opinion/el-telematico.html]

En dar gato por libro (13), se hace a referencia a un polémico programa educativo para que las familias tengan acceso a los libros escolares de forma gratuita. Además de que liebre y libro presentan similitud formal, esta desautomatización se hace eco de que el programa al que se hace referencia no cumple con los requisitos esperados en relación con la gratuidad de los libros escolares. Por otro lado, en dar gato por contrato (14), el referente es un contrato falso redactado por el protagonista del relato. De modo que, aunque se asemeja a un contrato real, no tiene validez. Finalmente, en el caso de dar gato por Puigdemont (15) también se hace referencia de forma irónica a un posible engaño: el hecho de que alguien se haga pasar por el político Carles Puigdemont. De manera que, aunque se le pareciera, no sería él.

Finalmente, en el tercer patrón encontramos aquellos casos en que solamente se mantiene la idea de engaño, puesto que, aunque se haya sustituido gato o liebre por otro elemento, no se expresa una comparación en relación con la calidad o naturaleza 
de algo, sino que incorporan un elemento nuevo en la locución al que, en algún caso, se ha hecho referencia en el contexto, pero no se comparan los dos ítems. Esto ocurre, por ejemplo, en dar gato por animal similar o dar paño por liebre (ej. 16-17):

(16)El director del genial delirio Ejecutivo ejecutor (1990) propone ahora un thriller inédito con maneras de telefilme. Un detective es contratado para un caso de aspecto sosegado. Las apariencias, de nuevo, confirman su tendencia a dar gato por animal similar. [El País. Fecha de acceso: 7 de junio de 2020. https://elpais.com/diario/1997/08/20/radiotv/872028013_850215.html]

(17) Esos son los únicos regalos que ha recibido la vicepresidenta pese a que los correveidiles del oprobio y las alcahuetas de la ofensa no se apeen del burro y continúen en sus trece (o en sus diecisiete). Propalando, urbi et orbi, que es una especialista en maquillaje y que acostumbra a dar paño por liebre. [ABC. Fecha de acceso: 7 de junio de 2020. https://www.abc.es/opinion/abci-dales-cana-mari-tere-200907140300-922517418972_noticia.html?ref=https\%3A\%2F\%2Fwww.google.es\%2F]

En el ejemplo (16), se ha sustituido liebre por la perífrasis animal similar. En este contexto, la UF desautomatizada parece funcionar en el sentido de 'engañar', pero no en relación con la calidad, sino con lo que uno espera. En este sentido, anteriormente se indica que «un detective es contratado para un caso de aspecto sosegado", a lo cual se añade que «las apariencias, de nuevo, confirman su tendencia a dar gato por animal similar». Por lo tanto, se da a entender que, aunque el caso por el cual el detective es contratado parece sosegado, en realidad no lo es. Por este motivo, podríamos decir que esta desautomatización no mantiene todos los aspectos de significado que vehicula la UF original dar gato por liebre. Por último, en dar paño por liebre (17), la palabra paño hace referencia a 'vestiduras' (acepción 15 del $D L E$ ), ya que en la noticia se expone un posible fraude cometido por la exvicepresidenta del Gobierno por el hecho de haber aceptado regalos en forma de ropa o de utilizar dinero público para comprar ropa. De nuevo, pues, la UF desautomatizada nos remite al engaño, pero en este caso pierde el matiz comparativo entre la calidad de dos productos que se asemejan. De esta forma, la sustitución de gato por paño en la locución hace aflorar que el motivo del engaño o, en este caso, del fraude, que es literalmente la ropa.

A continuación, nos centramos en la locución verbal coger el toro por los cuernos, que de acuerdo con el DLE significa 'enfrentarse resueltamente con una dificultad'. En este caso, el origen de la UF no se conoce con certeza, aunque existe la hipótesis que proceda de la mitología griega, en relación con Hércules y el toro de Creta. De hecho, encontramos diversas pinturas y esculturas que plasman ese relato mitológico, en que se observa a un hombre cogiendo a un toro por los cuernos. Esta hipótesis podría ser verosímil si tenemos en cuenta que este fraseologismo se usa en otras lenguas en el mismo sentido, como, por ejemplo, en inglés (to take the bull by the

Elisabeth LLOPART SAUMELL Desautomatización fraseológica: de la norma a la creatividad
CLINA

vol. 6-2, December 2020, 119-136

elSSN: 2444-1961

Ediciones Universidad de Salamanca - CC BY-NC-ND 
horns (Oxford English Dictionary)), francés (prendre le taureau par les cornes (Grand Robert)), portugués ('pegar o touro pelos cornos' (Priberam) o alemán ('den Stier bei den Hörnern packen' (Pons)). Independientemente de su origen, podemos tomar igualmente como sentido literal de la UF la imagen mental que proporcionan la suma de sus componentes.

En la Tabla 3, representamos el significado literal y el significado idiomático de la UF coger el toro por los cuernos:

\begin{tabular}{|l|l|l|}
\hline UF original & Sentido literal & Sentido idiomático \\
\hline Significado & \multicolumn{1}{|c|}{-} & $\begin{array}{l}\text { 'Enfrentarse resueltamente con } \\
\text { una dificultad’ }\end{array}$ \\
\hline Imagen mental & $\begin{array}{l}\text { Coger a un animal por los } \\
\text { cuernos }\end{array}$ & \\
\hline
\end{tabular}

Tabla 3. Representación del significado de la UF original coger el toro por los cuernos.

Respecto de la desautomatización de esta UF, podemos distinguir dos tipos de patrones, como se observa en la Tabla 4:

\begin{tabular}{|l|c|c|}
\hline UF desautomatizada & $\begin{array}{c}\text { Patrón 1: carácter semiliteral } \\
\text { e idiomático }\end{array}$ & Patrón 2: carácter idiomático \\
\hline Sentido literal & $\mathrm{x}$ & - \\
\hline Sentido idiomático & $\mathrm{x}$ & $\mathrm{x}$ \\
\hline Referencia & $\begin{array}{l}\text { Dificultad con referencia } \\
\text { animalística }\end{array}$ & Dificultad de cualquier tipo \\
\hline
\end{tabular}

Tabla 4. Patrones de desautomatización formal de coger el toro por los cuernos.

En las UF desautomatizadas del primer patrón, con carácter semiliteral e idiomático, se proyecta la imagen mental de coger un animal por los cuernos. En cambio, en el segundo patrón, se mantiene solamente el sentido idiomático de enfrentarse a un problema. En este caso, la dificultad en cuestión sustituye al toro en la UF original.

En cuanto al patrón número 1, vamos a analizar algunas UF desautomatizadas del tipo coger el/la x por los cuernos en las que se mantiene la referencia a un animal que también tiene cuernos, como el ciervo o el bisonte (ej. 18-19):

(18) Coger el ciervo por los cuernos

La Consejería de Presidencia censará la población y decidirá dónde pueden estar sin dañar la agricultura. [La Verdad. Fecha de acceso: 7 de junio de 2020. https://www.laverdad.es/murcia/20130202/local/region/coger-ciervo-cuernos-201302020959.html] 
(19) La cita fue apasionada y apasionante y quedó resuelta por detalles y, sobre todo, por el poso que demostró el conjunto cerámico que en el momento crítico del partido cuando supo olvidarse de sus dos derrotas consecutivas, coger el bisonte por los cuernos y asestar el golpe que a la postre sería definitivo. [Ahora, Noticias de Castilla-la Mancha. Fecha de acceso: 7 de junio de 2020. https:// ahoraclm.com/2018/11/04/fs-talavera-doma-y-vence-al-bisontes-castellon/]

En el contexto de coger el ciervo por los cuernos (18), el problema al que se hace referencia se corresponde literalmente con los ciervos, por el daño que causan en zonas agrícolas. Por este motivo, se utiliza la UF coger el toro por los cuernos, con el significado de enfrentarse a una dificultad, y se modifica para incluir el causante de este problema, el ciervo. De modo que, aunque se trata de un sentido figurado, en la locución se obtienen datos complementarios sobre la información que se quiere comunicar. En el ejemplo (19), en cambio, la referencia al bisonte no es literal, puesto que se trata de un equipo de fútbol sala que lleva por nombre Bisontes Castellón. De todos modos, la UF original permite crear, por un lado, la imagen mental de coger a un animal por los cuernos, correspondiente al sentido literal, y, del otro, explicar como el equipo rival es capaz de invertir la situación y ganar el partido, de acuerdo con el sentido idiomático.

Respecto del segundo patrón, observamos algunos casos en el cual toro ha sido sustituido por paro, agua y vermú (ej. 20-22):

(20) El PNV dice que «hay que coger el paro por los cuernos». [Diario Vasco. Fecha de acceso: 7 de junio de 2020. https://www. diariovasco.com/v/20130607/ bajo-deba/dice-coger-paro-cuernos-20130607.html]

(21) Existe una oportunidad de coger el agua por los cuernos y de solucionar el problema bajo la cobertura de los nuevos planes de cuenca. [La Verdad. Fecha de acceso: 7 de junio de 2020. https://www.laverdad.es/murcia/20080813/ region/coger-agua-cuernos-20080813.html]

(22) Esta obra es una ventana abierta a la realidad que se esconde detrás de la pared de todos los teatros. Miles de historias de actores y actrices refugiados tras un grifo de cerveza que se preguntan ¿cuántas cañas hay que poner para conseguir dar una réplica? Candela tendrá que apoyarse en su única amiga, una radio parlante, que le animará a coger el vermú por los cuernos y hacerse cargo de que sus sueños estén fuera de la barra. [Cádiz + Cerca. Fecha de acceso: 7 de junio de 2020. https://transparencia.cadiz.es/la-compania-zia-lamoraita-teatro-representara-toma-tu-pa-cana-en-las-noches-de-teatro/]

En coger el paro por los cuernos (20), la dificultad que se debe resolver es el paro, ya que a partir del contexto se sobreentiende que es alto $y$, por tanto, se deben buscar soluciones. En cuanto al ejemplo (21), coger el agua por los cuernos, hace referencia 
a los escasos recursos hídricos de una parte del territorio, de modo que da a entender que un posible trasvase podría ser la solución a este problema. En ambos casos, a partir de la UF original se puede reconstruir el significado de la UF modificada y señalar cual es la dificultad a la cual se están refiriendo. En último lugar, el vermú (22) no es un problema en sí, sino que se ha seleccionado esta bebida para evocar el hecho de servir copas en un bar. En este contexto, coger el vermú por los cuernos indica dejar de ejercer como camarero o camarera para dedicarse a la interpretación, es decir, trabajar como actor o actriz. Así pues, en vez de vermú, la palabra toro de la locución original se podría haber sustituido por otra bebida o elemento que recuerde trabajar en un bar. En comparación con los dos ejemplos anteriores, en este caso es más costoso comprender la información que se está comunicando, puesto que la relación entre el nuevo elemento que se ha inserido en la frase y la dificultad a la que se refiere no es tan directa, aunque está estrechamente relacionada.

En relación con el segundo patrón, también observamos algunos casos en que toro se sustituye por una unidad con sentido abstracto que no evoca un problema concreto, sino la determinación de seguir adelante y de enfrentarse a las posibles dificultades venideras. Por ejemplo, en los contextos en que toro se sustituye por vida y mundo (ej. 22-23).

(23) La periodista y presentadora Mara Torres presenta en 'La cara b' su nuevo libro, 'Los días felices', cinco años después de ganar el premio planeta por otro libro. «Es mucho mejor coger la vida por los cuernos", asegura la escritora. [Onda Cero. Fecha de acceso: 7 de junio de 2020. https://www.ondacero. es/programas/la-rosa-de-los-vientos/audios-podcast/mara-torres-el-libro-dice-mas-entre-lineas-de-lo-que-dice-el-texto_2017101559e327d30cf27ece4d44e728.html]

(24) Ingrid explica que su padre un día la instó a «dejarse de tonterías y coger el mundo por los cuernos". [XL Semanal. Fecha de acceso: 7 de junio de 2020. https://www.xlsemanal.com/conocer/20181121/masacre-utoya-anders-breivik-noruega-pelicula.html]

En el contexto de coger el mundo por los cuernos (ejemplo 23), la palabra mundo no se entiende en el sentido del planeta físico, sino como el 'conjunto de todo lo existente' y la 'sociedad humana' (DLE). De ahí se desprende el valor de seguir adelante, como también ocurre en coger la vida por los cuernos.

\section{CONCLUSIONES}

La desautomatización fraseológica es un recurso lingüístico que comprende una modificación deliberada de una UF en busca de un determinado valor estilístico. Esta 
intención creativa implica la transgresión de las normas establecidas en el uso, puesto que las UF forman parte del conocimiento compartido por los hablantes de una comunidad lingüística. De todas formas, como la UF modificada entraña una intención comunicativa determinada, la desautomatización no resulta inconcebible en relación con el sistema de la lengua, ya que el receptor debe ser capaz de comprender el significado, así como percibir los efectos expresivos de la unidad. En este sentido, la transgresión o explotación de la norma se considera un recurso lingüístico que permite jugar con la lengua, ya sea con fines expresivos o estéticos.

Asimismo, como la novedad de la UF desautomatizada no surge de la nada, ya que se basa en una UF que forma parte de los usos normales de los hablantes, y se emplea con una finalidad comunicativa, aunque sea más costoso para el receptor reconstruir el significado, se observan algunos patrones que guían la construcción de la desautomatización fraseológica de tipo formal. Estos patrones tienen en cuenta, por un lado, el significado literal de la UF o la imagen mental que se proyecta a partir de esta literalidad y, por el otro, el carácter idiomático de la UF original. En este sentido, cuantos más componentes compartan la UF original y la UF desautomatizada, más fácil será para el receptor comprender adecuadamente la intención comunicativa que subyace tras esta modificación creativa. En cambio, cuantos menos elementos tengan en común, tanto a nivel estructural como semántico, el significado concreto de dicha expresión resultará menos claro. A pesar de ello, si el receptor reconoce el fraseologismo que se esconde tras la expresión modificada, puede inferir el sentido general de la desautomatización.

Así pues, la creatividad de la desautomatización fraseológica como recurso que se desvía de las normas de uso compartidas por los hablantes presenta unos límites definidos: el sistema de la lengua. Y, además, aunque este afán creativo se explica por una voluntad expresiva, con el fin de llamar la atención y causar sorpresa, el objetivo final de este fenómeno es comunicar. Por este motivo, la modificación de la UF se encuentra delimitado por unos patrones determinados que permiten mantener el significado original de la expresión y, al mismo tiempo, introducir nueva información. Como hemos visto, en algunos casos estos patrones pueden ser muy productivos y dar lugar a numerosas desautomatizaciones.

\section{REFERENCIAS BIBLIOGRÁFICAS}

CorPas PAstor, Gloria. 1997. Manual de fraseología española. Madrid: Gredos.

Coseriu, Eugen. 1952. Sistema, norma y habla: con un resumen en alemán. Montevideo: Universidad de la República.

Díaz Orozco, Viviana. 2016. «La desautomatización de los refranes y fórmulas fijas del lenguaje». Revista Ciencia y Humanidades 3 (3): 35-58

[DLE] Real Academia Española. 2014. Diccionario de la lengua española (23a edición). Madrid: Real Academia Española, Espasa. Fecha de acceso: 15 de junio de 2020. http://dle.rae.es

Elisabeth LLOPART SAUMELL Desautomatización fraseológica: de la norma a la creatividad
CLINA

vol. 6-2, December 2020, 119-136

elSSN: 2444-1961

Ediciones Universidad de Salamanca - CC BY-NC-ND 
Guerrero SalazAr, Susana. 2017. "La desautomatización de las unidades fraseológicas en los titulares deportivos». Verba 44: 99-131.

[Grand Robert] Dictionnaires Le Robert. 2017. Le Grand Robert de la langue française. Fecha de acceso: 11 de enero de 2021. https://grandrobert.lerobert.com

Hanks, Patrick. 2013. Lexical Analysis: Norms and Exploitations. Cambridge, London: The MIT Press.

Koestler, Arthur. 1975. The Act of Creation. London: Pan Books.

MARTí SánCHEZ, Manuel. 2015. «La búsqueda de sentido en la desautomatización fraseológica». En Fraseología, didáctica y traducción, ed. por Pedro Mogorrón y Fernando Navarro. Frankfurt am Main: Peter Lang, 117-136.

Mena Martínez, Florentina. 2003. «En torno al concepto de desautomatización: aspectos básicos». Tonos Digital: Revista Electrónica de Estudios Filológicos 5. Fecha de acceso: 20 de mayo de 2020. https://digitum.um.es/digitum/handle/10201/50794.

Montoro del ARCo, Esteban. 2005. «Hacia una sistematización de la variabilidad fraseológica». En Estudios lingüísticos en recuerdo de del profesor Juan Martínez Marín, ed. por M. a Ángeles Pastor. Granada: Universidad de Granada, 125-152.

Moreno Nito, Juan Luis. 2015. «La desautomatización de las locuciones: cuando la afectividad adquiere forma en el español de Chile», e-AESLA, Revista digital 1. Fecha de acceso: 29 de mayo de 2020. https://cvc.cervantes.es/lengua/eaesla/pdf/01/65.pdf.

Oxford University Press. 2021. Oxford English Dictionary. Fecha de acceso: 11 de enero de 2021. http://Www.oed.com

Priberam Informática. 2020. Dicionário Priberam da Língua Portuguesa. Fecha de acceso: 11 de enero de 2021. https://dicionario.priberam.org

Pons. 2021. Diccionario Pons. Fecha de acceso: 11 de enero de 2021. https://es.pons.com

Pou, Rafael. «El neurofraude de las pseudociencias», Democrecía: revista de actualidad, cultura y pensamiento. Fecha de acceso: 3 de septiembre de 2020. https://democresia.es/pensamiento/neurofraude-las-pseudociencias-ciencia-materialismo/

Ruiz GuRiLlo, Leonor. 1997. «Relevancia y fraseología: la desautomatización en la conversación coloquial». Español actual: Revista de español vivo 68: 21-30.

SÁnCHEZ LóPEZ, Elena. 2015. «Phraseologization as a process of semantic change». Catalan Journal of Linguistics 14: 159-177.

Sánchez Manzanares, M. del Carmen. (2003). En Homenaje al profesor Estanislao Ramón Trives, ed. por Agustín Vera Luján, Ramón Almela Pérez, José M. Jiménez Cano y Dolores Anunciación Igualada Belchí. Murcia: Universidad de Murcia, Servicio de Publicaciones, 745-760.

Sanmartín Ortí, Pau. 2006. La finalidad poética en el formalismo ruso: el concepto de desautomatización. Tesis doctoral. Universidad Complutense de Madrid.

TIMOFEEVA, Larissa. 2005. «La ironía en las unidades fraseológicas». Interlingüística 16: 10691077.

TIMOFEEVA, Larissa. 2009. «La desautomatización fraseológica: un recurso para crear y divertir». En Estudios de lingüística: investigaciones lingüísticas en el siglo XXI, ed. por Juan Luis Jiménez Ruiz y Larissa Timofeeva. Alicante: Universidad de Alicante, 249-271.

Zuluaga, Alberto. 2001. «Análisis y traducción de unidades fraseológicas desautomatizadas». PhinN 16: 67-83.

Elisabeth LLOPART SAUMELL Desautomatización fraseológica: de la norma a la creatividad
CLINA

vol. 6-2, December 2020, 119-136

elSSN: 2444-1961

Ediciones Universidad de Salamanca - CC BY-NC-ND 